\title{
A 7-year retrospective review of renal trauma in paediatric patients in Johannesburg
}

\author{
NZ Mashavave, (D) A Withers, (iD) T Gabler, (iD V Lack, (iD) D Harrison, (iD) J Loveland (i) \\ Department of Paediatric Surgery, Chris Hani Baragwanath Academic Hospital, University of the Witwatersrand, South Africa
}

Corresponding author, email: nzxaba@gmail.com

Background: South African data on paediatric patients with renal trauma that are usually managed conservatively is scarce. This study aimed to review a 7-year experience of paediatric renal trauma and management.

Methods: A retrospective review of all paediatric admissions with renal injury was conducted in the Department of Paediatric Surgery, University of the Witwatersrand, between 1 January 2012 and 31 December 2018. Data from medical records reviewed included patient age, gender, mechanism of injury, severity of injury, management and length of hospital stay.

Results: Thirty-one patients with renal injuries were identified, of which 30 had complete data. Of these cases, 26/30 $(87 \%)$ sustained blunt renal injuries and $4 / 30(13 \%)$ were penetrating. The median age at presentation was 6 years, and $60 \%$ were females. Three patients had isolated renal injuries, and 23 had concomitant injuries including hepatic (9), thoracic (8), splenic (5), head (4), facial (3) and ureteric (1). Twenty-three patients were managed non-operatively. Two required renal exploration with resultant nephrectomies and one haemodynamically unstable patient died preoperatively. Four patients required operative intervention for concomitant injuries with no renal exploration. Two patients required ureteric stenting. The median length of hospital stay was 7 days (Range: 4-11 days, IQR 7 days).

Conclusion: Renal injuries in haemodynamically stable patients should be managed non-operatively. A 93\% renal preservation rate was achieved in this cohort of patients with nephrectomy performed only in haemodynamically unstable patients with Grade V injuries, in keeping with international norms.

Keywords: paediatric, renal injuries, conservative management, South Africa

\section{Introduction}

Trauma contributes significantly to paediatric morbidity and mortality, with 1.5 million injuries and 20000 deaths reported globally per annum, $90 \%$ of which are due to blunt abdominal trauma (BAT). ${ }^{1-4}$ It is estimated that $5-20 \%$ of paediatric patients that sustain BAT will sustain a renal injury.,5 Paediatric data regarding management of these patients in South Africa is scarce and, internationally, guidelines for the paediatric population have been developed from adult treatment protocols. ${ }^{6-8}$ Paediatric patients are more prone to renal injuries than adults due to numerous anatomical discrepancies. ${ }^{1,3,9-11}$ These include increased renal size in relation to the total body surface area, increased mobility of the kidney, less developed Gerota's fascia, decreased perirenal fat, weaker abdominal muscles, a less ossified thoracic cage and renal lobulations that permit natural transmission of forces along cleavage planes. $2,6,7,10,12$ Renal injury occurs in the presence of accelerationdeceleration forces and rarely occurs in isolation. ${ }^{6,12}$ The imaging modalities of choice are ultrasound with a fourphase computed tomography (CT) of the abdomen being the gold standard. ${ }^{6}$ The use of a Focused Assessment with Sonography for Trauma (FAST) is limited, operatordependent and should not be used as the only method of screening in haemodynamically stable paediatric patients. ${ }^{6}$ It has a specificity of $95 \%$ but a highly variable sensitivity of $33-89 \%{ }^{6}$

Over the past two decades, there has been a significant shift towards non-operative management (NOM) of paediatric renal injuries with success rates exceeding $85 \%$ in children up to 18 years of age. ${ }^{6,12,13}$ This has been enabled by the advances in research, technology and minimally invasive surgical aspects in the field. ${ }^{12,14}$ With its popularisation over the years, literature reports reduced nephrectomy rates, associated complications and length of hospital stay. ${ }^{14,15}$ The American Association for Surgery of Trauma (AAST) organ injury scale based on CT findings grades renal injuries from I to $\mathrm{V}^{12}$ NOM of low-grade (AAST I-III) renal injuries is well-accepted whilst less evidence is available for management of high-grade (AAST IV-V) renal injuries. ${ }^{16,17}$ Failure to respond to resuscitation, which manifests as haemodynamic instability, is the only absolute indication for operative management. ${ }^{16,17}$

This retrospective study aimed to document paediatric renal trauma in a level 1 trauma centre in a low- to middleincome country (LMIC), to identify deficits in care to improve outcomes at our institution and to compare these results to those found in local and international literature. 
Table I: Organ injury scale according to the American Association of Surgeons in Trauma

\begin{tabular}{ll}
\hline Renal injury scale of the American Association of Surgeons in Trauma \\
\hline Grade & Injury description \\
\hline I & $\begin{array}{l}\text { Contusion: microscopic or gross haematuria with normal findings of imaging studies } \\
\text { Haematoma: nonexpanding, subcapsular haematoma without parenchymal laceration }\end{array}$ \\
II & $\begin{array}{l}\text { Haematoma: nonexpanding perirenal haematoma confined to the retroperitoneum } \\
\text { Laceration: superficial lacerations }(<1 \mathrm{~cm} \text { depth) in the renal cortex }\end{array}$ \\
III & $\begin{array}{l}\text { Laceration: }>1 \mathrm{~cm} \text { in the renal cortex without extension into the collecting system or urinary extravasation } \\
\text { IV }\end{array}$ \\
Laceration: lacerations extending through the renal cortex, medulla and collecting system \\
Vascular: injuries to the main renal artery or vein with contained haemorrhage; thrombosis of a segmental artery without \\
parenchymal laceration
\end{tabular}

\section{Methods}

After approval from the Human Research and Ethics Committee (HREC-M181164), a retrospective record review of all paediatric patients under the age of 14 years who presented with renal injury to the Department of Paediatric Surgery, University of the Witwatersrand between 1 January 2012 and 31 October 2018 was conducted. Patient records, theatre registries, admission registers and the department's database were searched to identify patients who presented with urinary tract injury as a result of trauma within the study period. Demographic information, mechanism of injury, anatomical location of the injury, the grade of renal injury as per the AAST grading system as well as the treatment provided, and hospital length of stay were recorded. The American Association for Surgery of Trauma (AAST) organ injury scale based on CT findings grades renal injuries from I to $\mathrm{V}$ according to severity as detailed in Table I.

All haemodynamically stable patients had CT of the abdomen. AAST Grades I-III were defined as low-grade and grade IV-V as high-grade renal injuries. All cases were initially triaged by the emergency department team using advanced trauma life support, and care by the paediatric surgery team was instituted as early on as possible. Patients who were haemodynamically unstable did not receive a CT scan and were taken for immediate surgical exploration after resuscitation.

\section{Data analysis}

Data were entered onto an Excel spreadsheet and data analysis was performed using Statistica (Version 13 - Tibco Inc). Continuous variables, age and length of admission were noted to be non-parametric and are therefore expressed using the median and interquartile ranges (IQR). Categorical variables are expressed as proportions or percentages.

\section{Results}

Over the 5-year study period, 31 patients with renal injuries were identified, one was excluded due to incomplete clinical data for evaluation. Their ages ranged from 7 months to 11 years old. The median age at presentation was 6 years (IQR $3-9)$, and $60 \%$ were females.

Blunt renal trauma occurred in $26 / 30(87 \%)$ cases and penetrating in $4 / 30(13 \%)$. The most common mechanism of injury was pedestrian-vehicular collisions (16/30; 53\%), followed by falls $(8 / 30 ; 26 \%)$. In the penetrating injury category, gunshot wounds (GSWs) occurred in 3/30 (10\%) and iatrogenic (post needle biopsy) in 1/30 (3\%) as shown in Table II. Twenty-eight (93\%) haemodynamically stable patients were diagnosed by CT imaging with intravenous contrast. Of the three haemodynamically unstable patients with renal injuries, two were diagnosed intraoperatively and one died before surgical intervention. Twenty-eight patients had documented grades of renal injuries. The renal injuries were distributed as follows: grade I, $n=4 / 28$ (14\%); grade II, $n=8 / 28$ (29\%); grade III, $n=4 / 28(14 \%)$; grade IV, $n=6 / 28$ (21\%); grade $\mathrm{V}, n=6 / 28(21 \%)$. Three patients had isolated renal injuries, 23 had concomitant injuries, and four were undocumented. Table III shows the different concomitant injuries at various grades of renal injury.

\begin{tabular}{lccc}
\multicolumn{4}{l}{ Table II: Mechanism of injury } \\
\hline $\begin{array}{l}\text { Mechanism of } \\
\text { injury }\end{array}$ & $\begin{array}{c}\text { Number } \\
(\boldsymbol{n}=\mathbf{3 0})(\%)\end{array}$ & $\begin{array}{c}\text { Low-grade } \\
(\text { I-III) }\end{array}$ & $\begin{array}{c}\text { High-grade } \\
(\mathbf{I V}-\mathbf{)})\end{array}$ \\
\hline PVC & $16(53)$ & $10(33)$ & $6(20)$ \\
MVC & $2(7)$ & $2(7)$ & 0 \\
Falls & $8(26)$ & $4(13)$ & $4(13)$ \\
Gunshot & $3(10)$ & $2(7)$ & $1(3)$ \\
Iatrogenic & $1(3)$ & $1(3)$ & 0
\end{tabular}

Table III: Different grades of renal injury and the number of associated concomitant injuries

\begin{tabular}{lccccccccccc}
\hline $\begin{array}{l}\text { Grade of } \\
\text { renal injury }\end{array}$ & $\begin{array}{c}\text { Head } \\
\text { injuries }\end{array}$ & $\begin{array}{c}\text { Facial } \\
\text { fractures }\end{array}$ & $\begin{array}{c}\text { Thoracic/ } \\
\text { pulmonary }\end{array}$ & Liver & Spleen & Bowel & Skeletal & Ureteric & $\begin{array}{c}\text { Isolated } \\
\text { Total } \\
\boldsymbol{n}(\%)\end{array}$ \\
\hline Grade I & 0 & 0 & 1 & 0 & 0 & 0 & 1 & 0 & 1 & $3(8)$ \\
Grade II & 1 & 1 & 4 & 3 & 1 & 1 & 0 & 0 & 0 & $11(30)$ \\
Grade III & 0 & 0 & 0 & 3 & 0 & 0 & 1 & 0 & 0 & $4(11)$ \\
Grade IV & 1 & 1 & 2 & 2 & 3 & 0 & 1 & 1 & 0 & $11(30)$ \\
Grade V & 2 & 1 & 1 & 1 & 1 & 0 & 0 & 0 & 2 & $8(22)$
\end{tabular}


Twenty-three $(77 \%)$ renal injuries were managed nonoperatively, two required renal exploration with resultant nephrectomies already mentioned. Four (13\%) patients required operative intervention for concomitant injuries without renal exploration. Two patients required ureteric stenting: one for a combined grade IV renal and ureteric injury after an iatrogenic renal biopsy injury, and one for a grade IV gunshot injury with urinary extravasation.

Of the grade $\mathrm{V}$ injuries, four were managed nonoperatively and two (7\%) underwent operative intervention with resultant nephrectomy. Out of the 30 patients, two (7\%) died. No angio-embolisation procedures were performed. The median length of hospital stay was 7 days (range 4-11 days, IQR 7 days).

Complications, length of bed rest, CT scan re-imaging and long-term follow-up of patients beyond discharge were not investigated. This is due to the retrospective nature of this study, difficulty in locating patient files at follow-up and patients lost to follow-up.

\section{Discussion}

Blunt injury remains the commonest cause of renal trauma in the paediatric population. In this study, $87 \%$ of patients sustained blunt renal trauma. The mechanisms of injury are dependent on the geographical area of the patient cohorts. For instance, in Hawaii, 33\% of patients below the age of 18 years sustained renal injuries whilst surfing, whereas, in the Alpine countries, skiing accidents account for $36 \%$ of renal injuries in patients between ages $2-17$ years. ${ }^{1,10}$ In our setting, pedestrian-vehicular collisions (PVC) accounted for the majority of blunt abdominal trauma (53\%) followed by falls $(26 \%)$. This distribution was also demonstrated in a South African study by Tsui et al. in which $44 \%$ of patients were involved in PVCs, and 31\% were due to falls. ${ }^{3}$ Another South African study by Bass et al. showed $73.6 \%$ patients were involved in PVCs and $13.4 \%$ were due to falls. ${ }^{18}$ Our distribution of blunt renal injury in South Africa differs to a multisystemic review of 458 paediatric patients by Voelzke and Leddy in the United States, where $30 \%$ of renal injuries were secondary to motor vehicle collisions (MVCs), 27\% falls, and $13 \%$ to PVCs. ${ }^{19}$ Also, children are three times more likely than adults to become victims of pedestrian accidents. ${ }^{19}$ This shows a lack of road safety in both LMICs and high-income countries. However, this is more distinct in LMICs. Increased urbanisation, lack of children supervision, poor road infrastructure and non-roadworthy vehicles may be the predisposing factors.

Blunt renal injuries rarely occur in isolation.,12 This is demonstrated in our study, where $77 \%$ of cases presented with concomitant injuries. Hepatic and splenic lacerations were the most common intra-abdominal injuries, with the most common extra-abdominal being thoracic. This frequency was similar to those reported in two other South African studies. ${ }^{3}$ In our study, renal injuries with concomitant injuries were not explored intraoperatively, which resulted in higher renal preservation rates. ${ }^{3}$

Penetrating gunshot injuries were seen in only $10 \%$ of our patients. Interestingly, all three patients in our study underwent surgical intervention for concomitant injuries, without any renal exploration as preoperative imaging outlined the grade of renal injury and associated injuries, and they remained haemodynamically stable. Selective NOM of gunshot renal trauma has high renal salvage rates and favourable outcomes. ${ }^{20}$ Injuries with stable peripheral haematomas do not warrant exploration. ${ }^{20,21}$ There is paucity of data regarding penetrating renal injuries in the paediatric population. Penetrating renal injuries most commonly occur in the paediatric population above 14 years of age..$^{22}$ In a 2-year study in children between 5 and 18 years, Angus et al. reported that 25 of 60 patients undergoing laparotomy had sustained renal trauma. ${ }^{23}$ Eighty-four per cent of these 25 patients had sustained GSW, 12\% stab wounds and 4\% blunt trauma. ${ }^{23}$ Only 16\% required nephrectomy and $84 \%$ required renal-sparing procedures. ${ }^{23}$ Though the numbers in our study are small, patients with penetrating renal injury who are haemodynamically stable should be afforded the opportunity as blunt injuries for NOM with close monitoring.

Historically, grade $\mathrm{V}$ injuries were managed surgically. Two patients in our study with grade $\mathrm{V}$ blunt renal injuries underwent nephrectomy due to haemodynamic instability, with an overall nephrectomy rate of $7 \%$. Sixty-seven per cent of patients with grade $\mathrm{V}$ injuries were managed nonoperatively, which is in keeping with data described in literature; however, we experienced lower nephrectomy rates possibly due to absence of major renovascular injuries seen in our cohort. ${ }^{8,13}$ A review by Eassa et al. demonstrated a $22 \%$ nephrectomy rate 1 to 21 days post-injury, this due to suspected major vascular injuries. ${ }^{13}$ Fifty per cent of their patients with grade $\mathrm{V}$ injuries were successfully managed conservatively, and over $75 \%$ had renal preservation. ${ }^{13}$ With respect to their NOM, 11\% had selective lower-pole arterial embolisation, $17 \%$ had percutaneous drainage of progressive symptomatic urinomas and two required delayed surgery for ureteropelvic junction avulsion. ${ }^{13} \mathrm{NOM}$ of grade IV and V injuries has become the cornerstone as it is associated with fewer nephrectomies regardless of mechanisms of injury, and our study confirms that this practice is safe. ${ }^{8}$

Two patients with AAST grade IV renal injuries (one with a large perinephric haematoma) were successfully treated with double-J stents for urinary extravasation and ascites, and ureteric injury after a gunshot and iatrogenic injury respectively. No patients underwent percutaneous drainage of the urinoma, percutaneous nephrostomy or renorrhaphy. In a retrospective review of 26 children with grade IV renal injury by Lee et al., eight (31\%) required urological intervention. ${ }^{24}$ Five of eight $(63 \%)$ were treated successfully by ureteral stenting with or without percutaneous drainage for urinoma, two of eight $(25 \%)$ required percutaneous nephrostomy and one $(12 \%)$ underwent a renorrhaphy. ${ }^{24}$ From this study and the above data, urologic intervention can be successfully employed in haemodynamically stable patients with urine and contrast extravasation, large perinephric haematoma and anteromedially-located lacerations. ${ }^{24}$ Presence of the above predictors requires cautious observation, timely imaging and appropriate early intervention. ${ }^{24}$

Trans-arterial embolisation (TAE) was not used in our study due to lack of infrastructure and technical skill. Even though TAE has established use in the adult population, it is seldom used in children due to the smaller arterial size and concerns of procedure-related complications and safety. ${ }^{25}$ Angiography and selective TAE can be used after the detection of active haemorrhage on CT scan in stable patients being treated conservatively. ${ }^{25}$ Indications for TAE include parenchymal laceration with contrast extravasation or perirenal haematoma, or the presence of an arteriovenous fistula or pseudoaneurysm with evidence of persistent 
bleeding. ${ }^{25}$ There were no identifiable cases in our cohort with such factors mentioned above.

The length of hospital admission in our study ranged from 4-11 days with one mortality reported. Tsui et al. found that their length of admission ranged from 4-132 days with all 16 of their patients discharged without mortality. ${ }^{3}$ NOM allows for less time spent in ICU and in hospital overall, less blood transfusion and lower incidences of long-term complications. $^{3}$

Several limitations of this study should be observed. It was a retrospective study of patient records with limited data, reviewed from two academic institutions. This limited important parameters that were not evaluated, such as admission presence of haematuria, need for blood transfusion and re-imaging modalities used. Also, patients were managed by different surgeons over an extended period with a relatively small patient cohort.

\section{Conclusion}

This study had a 93\% renal preservation rate and confirms that renal injuries in haemodynamically stable paediatric patients can and should be managed non-operatively even in those with concomitant injuries or very severe grade renal injuries. Complications in this latter group can be managed by minimally invasive urologic and endovascular intervention techniques. Lack of follow-up, especially for the severe grade injuries treated conservatively, means that long-term detrimental sequelae of this approach are undetermined. In common with other South African studies, a high proportion of patients sustained blunt abdominal trauma due to PVCs, which highlights the need for urgent public road safety interventions.

\section{Conflict of interest}

The authors declare no conflict of interest.

\section{Funding source}

None.

\section{Ethical approval}

Ethical approval was obtained from the University of the Witwatersrand Human Research Ethics Committee (M181164).

\section{ORCID}

NZ Mashavave (iD https://orcid.org/0000-0002-1523-6118

A Withers (iD https://orcid.org/0000-0001-5941-9824

T Gabler (iD) https://orcid.org/0000-0002-2761-6687

V Lack (iD https://orcid.org/0000-0003-0553-0492

D Harrison (iD https://orcid.org/0000-0002-7093-1383

J Loveland (iD https://orcid.org/0000-0002-3341-0749

\section{REFERENCES}

1. Richards CR, Clark ME, Sutherland RS, Woo RK. Retrospective review of paediatric blunt renal trauma - a single institution's five-year experience. Hawaii J Med Public Health. 2017;76(5):119-22.

2. Buckley CJ, Mcaninch JW. The diagnosis, management and outcomes of paediatric renal injuries. Urol Clin North Amer. 2006;33(1):33-40.

3. Tsui A, Lazarus J, Van As S. Non-operative management of renal trauma in very young children - experiences from a dedicated South African paediatric trauma unit. Injury. 2012;43(9):1476-81.
4. Umbreit EC, Routh JC, Husmann DA. Non-operative management of nonvascular grade IV blunt renal trauma in children - meta-analysis and systematic review. Paediatr Urol. 2009;74(3):579-82.

5. Ishida Y, Tyroch AH, Emami N, McLean SF. Characteristics and management of blunt renal injury in children. J Emerg Trauma Shock. 2017;10(3):140-5.

6. Fernandez-Ibieta M. Renal trauma in paediatrics - current review. Urology. 2018;113:171-8.

7. Albal M, Rode A, Bansod PY, Albal V. Paediatric renal trauma: conservative management. Int J Biomed Res. 2015;6(5):3468 .

8. Jacobs MA, Hotaling JM, Mueller BA, et al. Conservative management vs early surgery for high grade paediatric renal trauma--do nephrectomy rates differ. J Urol. 2012;187(5):181722.

9. LeeVan E, Zmora O, Cazzulino F, et al. Management of paediatric blunt renal trauma - systematic review. J Trauma Acute Care Surg. 2015;80(3):519-28.

10. Radmayr C, Oswald J, Muller E, Holtl L, Bartsch G. Blunt renal trauma in children -26 years clinical experience in an Alpine region. Eur Urol. 2002;42(3):297-300.

11. Agrawal A, Agrawal CS, Kumar A, et al. Epidemiology and management of paediatric head injury in eastern Nepal. Afr J Paediatr Surg. 2008;5(1):15-8.

12. Elrich T, Kitrey ND. Renal trauma - the current best practice. Ther Adv Urol. 2018;10(10):295-303.

13. Eassa W, El-Ghar MA, Jednak R, El-Sherbiny M. Nonoperative management of grade 5 renal injury in children does it have a place? Eur Urol. 2010;57(1):154-61.

14. Da Costa IA, Amend B, Stenzl A, Bedke J. Contemporary management of acute kidney trauma. Journal Acute Disease. 2016;5(1):29-36.

15. McCombie SP, Thyer I, Corcoran NM, et al. The conservative management of renal trauma a literature review and practical clinical guideline from Australia and New Zealand. Br J Urol. 2014;114(1):13-21.

16. Hagedorn JC, Fox N, Ellison J, et al. Pediatric blunt renal trauma practice management guidelines. Collaboration between the Eastern Association for the Surgery of Trauma and the Pediatric Trauma Society. J Trauma. 2019;86(5):91625.

17. Notrica DM, Linnaus ME. Nonoperative management of blunt solid organ injury in pediatric surgery. Surg Clin North Am. 2017;97(1):1-20.

18. Bass DH, Semple PL, Cywes S. Investigation and management of blunt renal injuries in children - a review of 11 years' experience. J Pediatr Surg. 1991;26(2):196-200.

19. Voelzke BB, Leddy L. The epidemiology of renal trauma. Transl Androl Urol. 2014;3(2):143-9.

20. Velhamos GC, Demetriades D, Cornwell EE, et al. Selective managment of renal gunshot wounds. Br J Surg. 1998;85(8):1121-4.

21. Voelzke BB, McAninch JW. Renal gunshot wounds - clinical management and outcome. J Trauma. 2009;66(3):593-601.

22. Coccolini F, Moore E, Kluger Y, et al. Kidney and urotrauma - WESE-AAST guidelines. World J Emerg Surg. 2019;14(1):54.

23. Angus LD, Tachmes L, Kahn S, et al. Surgical management of paediatric renal trauma - an urban experience. Am Surg. 1993;59(6):388-94.

24. Lee JN, Lim JK, Woo MJ, et al. Predictive factors for conservative treatment failure in grade IV paediatric blunt renal trauma. J Paediatr Urol. 2016;12(2):93.

25. Lin $\mathrm{WC}$, Lin $\mathrm{CH}$. The role of interventional radiology for paediatric blunt renal trauma. Ital J Paediatr. 2015;41:76. 